\title{
Tumor lysate-based vaccines: on the road to immunotherapy for gallbladder cancer
}

\author{
Daniel Rojas-Sepúlveda ${ }^{1,2,3} \cdot$ Andrés Tittarelli ${ }^{1,2}$ - María Alejandra Gleisner ${ }^{1,2} \cdot$ Ignacio Ávalos $^{1,2}$. \\ Cristián Pereda ${ }^{1,2}$. Iván Gallegos ${ }^{5}$. Fermín Eduardo González ${ }^{2,4} \cdot$ Mercedes Natalia López $^{1,2}$ • Jean Michel Butte ${ }^{6}$. \\ Juan Carlos Roa ${ }^{7,8} \cdot$ Paula Fluxá ${ }^{1,2} \cdot$ Flavio Salazar-Onfray ${ }^{1,2}$ (B)
}

Received: 1 September 2017 / Accepted: 26 March 2018 / Published online: 29 March 2018

(c) The Author(s) 2018

\begin{abstract}
Immunotherapy based on checkpoint blockers has proven survival benefits in patients with melanoma and other malignancies. Nevertheless, a significant proportion of treated patients remains refractory, suggesting that in combination with active immunizations, such as cancer vaccines, they could be helpful to improve response rates. During the last decade, we have used dendritic cell (DC) based vaccines where DCs loaded with an allogeneic heat-conditioned melanoma cell lysate were tested in a series of clinical trials. In these studies, $60 \%$ of stage IV melanoma DC-treated patients showed immunological responses correlating with improved survival. Further studies showed that an essential part of the clinical efficacy was associated with the use of conditioned lysates. Gallbladder cancer (GBC) is a high-incidence malignancy in South America. Here, we evaluated the feasibility of producing effective DCs using heat-conditioned cell lysates derived from gallbladder cancer cell lines (GBCCL). By characterizing nine different GBCCLs and several fresh tumor tissues, we found that they expressed some tumor-associated antigens such as CEA, MUC-1, CA19-9, Erb2, Survivin, and several carcinoembryonic antigens. Moreover, heat-shock treatment of GBCCLs induced calreticulin translocation and release of HMGB1 and ATP, both known to act as danger signals. Monocytes stimulated with combinations of conditioned lysates exhibited a potent increase of DCmaturation markers. Furthermore, conditioned lysate-matured DCs were capable of strongly inducing $\mathrm{CD} 4^{+}$and $\mathrm{CD} 8^{+} \mathrm{T}$ cell activation, in both allogeneic and autologous cell co-cultures. Finally, in vitro stimulated CD $8^{+} \mathrm{T}$ cells recognize HLAmatched GBCCLs. In summary, GBC cell lysate-loaded DCs may be considered for future immunotherapy approaches.
\end{abstract}

Keywords Melanoma · Gallbladder cancer · Dendritic cells · Tumor lysates · Immunotherapy · CITIM 2017

\section{Abbreviations}

$\mathrm{AM}$ BAGE

Activated monocytes

B melanoma antigen

Prior to presentation at CITIM 2017 in Prague, part of this work was also presented at the International Congress of Immunology (ICI), 21-26 August 2016, Melbourne, Australia. An abstract was published in [1]. Following presentation at CITIM 2017, part of this work was also presented at IMMUNOLOGY 2017, 12-16 May 2017, Washington, USA. An abstract was published in [2].

This paper is a Focussed Research Review based on a presentation given at the Fifth International Conference on Cancer Immunotherapy and Immunomonitoring (CITIM 2017), held in Prague, Czech Republic, $24^{\text {th }}-27^{\text {th }}$ April 2017. It is part of a series of Focussed Research Reviews and meeting report in Cancer Immunology, Immunotherapy.

Flavio Salazar-Onfray

fsalazar@u.uchile.cl

Extended author information available on the last page of the article
CA19-9

CCR7

CEA

CXCR

DAMPs

DC

eCRT

FBS

GAGE

GBC

GBCCL

HLA

HMGB 1

IFN- $\gamma$

iMFI

MAGE

M2-DCs

M3-DCs
Cancer antigen 19-9

C-C chemokine receptor type 7

Carcinoembryonic antigen

C-X-C motif chemokine receptor

Damage associated molecular patterns

Dendritic cell

Extracellular (or exo) calreticulin

Fetal bovine serum

$\mathrm{G}$ antigen

Gallbladder cancer

Gallbladder cancer cell line

Human leukocyte antigen

High mobility group box-1

Interferon gamma

Integrated mean fluorescence intensity

Melanoma-associated antigen

Dendritic cells matured with M2 lysate

Dendritic cells matured with M3 lysate 


$\begin{array}{ll}\text { M5-DCs } & \text { Dendritic cells matured with M5 lysate } \\ \text { M8-DCs } & \text { Dendritic cells matured with M8 lysate } \\ \text { mAbs } & \text { Monoclonal antibodies } \\ \text { MHC } & \text { Major histocompatibility complex } \\ \text { MUC-1 } & \text { Mucin-1 } \\ \text { PBMC } & \text { Peripheral blood mononuclear cells } \\ \text { rhGM-CSF } & \text { Recombinant human granulocyte-mac- } \\ & \text { rophage colony-stimulating factor } \\ \text { rhIL } & \text { Recombinant human interleukin } \\ \text { TAAs } & \text { Tumor associated antigens } \\ \text { Th1 } & \text { Type 1 T helper cells } \\ \text { Th2 } & \text { Type 2 T helper cells } \\ \text { TNF- } \alpha & \text { Tumor necrosis factor } \alpha \\ \text { TRIMEL-DCs } & \text { Dendritic cells matured with TRIMEL }\end{array}$

\section{Introduction}

The recent use of immune-checkpoint blocker antibodies has demonstrated durable clinical benefits in patients with melanoma, lung cancer and other solid tumors [3-9]. Despite this relevant clinical performance, a high percentage of treated patients remains refractory, strongly suggesting that the combination with active immunizations may be useful to improve the response rates of those patients. In this context, cancer vaccines, particularly dendritic cell (DC)based vaccines, can be used as complementary treatments in cancer patients. Optimal delivery of a wide-ranging pool of tumor-associated antigens (TAAs) and the use of adequate adjuvants are shown to be crucial for vaccine success [10]. During the last decade, we have been able to produce therapeutic DCs using an allogeneic heat-conditioned melanoma cell lysate named TRIMEL. Sixty percent of advanced melanoma patients treated with these DCs showed a delayed type hypersensitivity reaction against TRIMEL, which correlated with a threefold prolonged survival [11]. This strategy provides a reproducible pool of almost all the potential melanoma-associated antigens, suitable for use in a wide range of patients independent of their major histocompatibility complex (MHC) haplotypes or the availability of autologous tumor tissue [12]. Moreover, we previously showed that TRIMEL contains some heat shock-induced damageassociated molecular patterns (DAMPs), such as high mobility group box-1 (HMGB1) and calreticulin (eCRT), which mediate an optimal maturation, activation and antigen crosspresentation of the monocyte-derived DCs, and thus enable them to activate antigen-specific $\mathrm{T}$ cells [13]. However, the development of an optimal allogeneic tumor cell lysate preparation for different tumor types is crucial to expand the use of these approaches for different cancers.

Gallbladder cancer (GBC) is the most common cancer of the biliary tree. Although GBC is infrequent in developed countries [14], in South America and particularly in Chile, this tumor constitutes a major health problem [14-17]. The underlying causes for the high risk of GBC in these areas are unclear, but several important risk factors probably contribute, including chronic inflammation caused by gallstones, high obesity rates and genetic susceptibility in women of indigenous Mapuche ancestry, in which the incidence increases to 27.3 cases per $100,000[14,16,17]$.

Early detection and diagnosis of GBC is complicated because the clinical symptoms are manifested in advanced stages. The average survival time for patients with advanced, non-resectable GBC varies from 4 to 14 months $[17,18]$. The most effective treatment for this type of cancer is surgical removal of the primary tumor and areas of local extension. Unfortunately, less than $10 \%$ of patients have resectable tumors, and nearly $50 \%$ of them present metastasis at the time of diagnosis [19]. Even with surgery, most of the GBC patients progress to a metastatic stage, highlighting the need for novel adjuvant therapies, such as immunotherapy.

The purpose of this study was to investigate the immunogenicity of several combinations of tumor lysates derived from different GBC cell lines (GBCCL) and their effect on monocyte differentiation and activation to DCs and their capacity to induce an in vitro $\mathrm{T}$ cell-mediated antiGBC response. In this respect, a major requirement for the potential clinical effectiveness of GBC lysate-loaded DCs is to investigate the presence of shared TAAs in GBCCL and in fresh tumor tissues. Our results suggest that human DCs matured with specific GBCCL heat shock-conditioned lysates are capable of inducing specific $\mathrm{T}$ cells activation against this tumor and can be considered for the development of future immunotherapeutic approaches for GBC patients.

\section{Materials and methods}

\section{Cell lines and cell lysates}

GBCCL GBd1 (CVCL_H705), G415 (CVCL_8198), OCUG-1 (CVCL_3083), NOZ (CVCL_3079), TGBC1TKB (CVCL_1769; hereafter 1TKB), TGBC-2TKB (CVCL_3339; hereafter 2TKB), TGBC-14TKB (CVCL_3340; hereafter 14TKB) and TGBC-24TKB (CVCL_1770; hereafter 24TKB) were provided by Juan Carlos Roa (Department of Pathology, Pontificia Universidad Católica de Chile, Santiago, Chile). The GBCCL CAVE was established in our lab from a primary adenocarcinoma GBC tumor sample from a Chilean patient. NOZ, GBd1 and G415 cells were grown in RPMI 1640 culture medium (Corning, NY, USA), whereas OCUG-1, 1TKB, 2TKB, 14TKB, 24TKB and CAVE were grown in DMEM culture medium (Corning, NY, USA). Culture media were supplemented with $10 \%$ fetal bovine serum (FBS), $10 \mathrm{U} /$ 
$\mathrm{mL}$ penicillin and $10 \mathrm{mg} / \mathrm{mL}$ streptomycin (Corning, NY, USA). Cells were maintained at $37{ }^{\circ} \mathrm{C}$ under $5 \% \mathrm{CO}_{2}$ and $95 \%$ relative humidity.

Cell lysates were produced as previously described [13]. Briefly, for individual GBCCL lysates, $4 \times 10^{6}$ cells $/ \mathrm{mL}$ were heat shocked at $42{ }^{\circ} \mathrm{C}$ for $1 \mathrm{~h}$, incubated for $2 \mathrm{~h}$ at $37{ }^{\circ} \mathrm{C}$ and then lysed. For GBCCL combined lysates, cells were mixed in equal amounts to achieve a final concentration of $4 \times 10^{6}$ cells $/ \mathrm{mL}$, and heat shocked as described before. The mixed cell lysates evaluated were made as follows: M1 (24TKB + GBd1+G415); $\mathrm{M} 2$ (2TKB + 24 TKB + GBd 1); M 3 $(1 \mathrm{TKB}+2 \mathrm{TKB}+24 \mathrm{TKB}) ; \mathrm{M} 4(\mathrm{OCUG} 1+\mathrm{GBd} 1+\mathrm{G} 415)$; M5 (2TKB + G415 + OCUG1); M6 (NOZ + OCUG $1+\mathrm{G} 415) ; \mathrm{M} 7(1 \mathrm{TKB}+14 \mathrm{TKB}+24 \mathrm{TKB}) ;$ and $\mathrm{M} 8$ $(24 \mathrm{TKB}+$ OCUG1 + G415).

\section{Antibodies}

Monoclonal antibodies (mAbs) against human carcinoembryonic antigen (CEA; clone COL-1), erbB2 (clone 3B5), and survivin (clone 8E2) were purchased from Thermo Fisher Scientific (Waltham, Massachusetts, USA). mAbs against human mucin-1 (MUC-1; clone HMFG1), cancer antigen 19-9 (CA19-9; clone SPM110) and calreticulin (clone FMC 75) were purchased from Abcam (Cambridge, USA). mAbs against human CD3 eFluor450 (clone SK7), human leukocyte antigen (HLA)-DR APC eFluor780 (clone LN3), CD83 PE Cy7 (clone HB15e), CD25 PerCP Cy5.5 (clone BC96), CD69 PE (clone FN50) and interleukin (IL)-4 PE Cy7 (clone 8D4-8) were purchased from eBioscience (San Diego, CA, USA). mAbs against human CD8 PE Cy7 (clone SK1), C-C chemokine receptor type 7 (CCR7) PE (clone G043H7), CD4 APC Cy7 (clone RPA-T4), tumor necrosis factor (TNF)- $\alpha$ PerCP (clone Mab11) and interferon (IFN)- $\gamma$ AlexaFluor 647 (clone 4S.B3) were purchased from BioLegend (San Diego, CA, USA). Polyclonal goat antimouse $\mathrm{IgG}$ antibody was purchased from eBioscience. mAbs against human HLA-ABC (clone G46-2.6), CD80 BV421 (clone L307.4), CD86 BB515 (clone 2331), C-X-C motif chemokine receptor (CXCR)3 APC (clone 1C6/CXCR3) and CXCR4 APC (clone 12G5) were purchased from BD Pharmingen (San Diego, CA, USA).

\section{Flow cytometry}

The surface expression of MUC-1, erbB2, survivin, CA19-9, $\mathrm{CEA}$, and eCRT was analyzed by flow cytometry. Intracellular staining was performed with the Foxp3/Transcription Factor Fixation/Permeabilization Concentrate and Diluent kit (eBioscience). Live/dead kit (Thermo Fisher) was used for live/dead cell discrimination. Flow cytometry was conducted on a FACSVerse flow cytometer (BD Biosciences) and data analysis was performed using the FlowJo software (Tree Star, Inc., Ashland, OR, USA).

\section{Reverse transcription polymerase chain reaction (RT-PCR)}

Total RNA was extracted from cells using TriPure reagent (Roche) and used to determine the expression and relative level of the Melanoma-associated antigen (MAGE), G antigen (GAGE) and B melanoma antigen (BAGE) in GBCCL. cDNAs were synthesized with M-MLV Reverse Transcriptase (Life Technologies). PCR was performed using cDNA template in the MasterCycler (Eppendorf), according to the manufacturer's instructions. The sequences of the used primers are available under request.

\section{Immunohistochemistry}

Sections of $3 \mu \mathrm{m}$ thickness from paraffin-embedded GBC tissues were mounted on slides, rehydrated and antigen retrieval was performed by heat in Tris-EDTA pH 9.0 or citrate buffer $\mathrm{pH} 6.0$ depending on the Ab used. Primary Abs were used according to manufacturer's instructions (CEA dilution 1:200, clone COL-1, Thermo Scientific; MUC-1 dilution 1:200, clone HMFG1, Abcam; erbB2 dilution 1:200, clone 3B5, Thermo Scientific; CA19-9 dilution 1:50, clone SPM110, Abcam; and survivin dilution 1:50, clone 8E2, Thermo Scientific). The slides were incubated with primary Abs in a moist chamber overnight at $4{ }^{\circ} \mathrm{C}$. After incubation with primary Abs, slides were washed with TBS before incubation with labeled secondary Abs for $1 \mathrm{~h}$ at $4{ }^{\circ} \mathrm{C}$. Sections were subsequently incubated with $\mathrm{ABC}$ solution for 30 min (ABC Vectastain Kit Elite PK6200, Vector Laboratories), washed with three changes of TBS, incubated with Dako-Chromogen solution and washed with deionized water. Background staining was performed with Mayer's hematoxylin, sections were dehydrated through ascending alcohols to xylene and mounted. Negative control slides omitting the primary $\mathrm{Ab}$ were included in all batches. An expert pathologist evaluated the expressions of CEA, MUC1, c-erbB2, CA19-9 and survivin in GBC tissues.

\section{Enzyme-linked immunosorbent assay (ELISA)}

The concentration of HMGB 1 in $100 \mu \mathrm{L}$ of supernatants from control and heat shocked GBCCL $\left(4 \times 10^{6}\right.$ cells $\left./ \mathrm{mL}\right)$ were measured by ELISA using a specific HMGB1 ELISA kit according to the manufacturer's instructions (CloudClone Corp.). $450 \mathrm{~nm}$ optical densities were measured in a Sunrise absorbance reader (Tecan). 


\section{ATP determination}

The concentration of ATP in supernatants from control and heat shocked GBCCL $\left(4 \times 10^{6}\right.$ cells $\left./ \mathrm{mL}\right)$ was measured by the Luciferase-Based ATP Determination Kit (Life Technologies) according to the manufacturer's instructions. Luminescence was measured in a TopCount luminescence counter (PerkinElmer).

\section{DC generation}

Adherent monocytes isolated from peripheral blood mononuclear cells (PBMC) of healthy donors from the Centro Metropolitano de Sangre y Tejidos, Hospital Metropolitano (Santiago, Chile) were cultured in serum-free AIM-V medium (Invitrogen) for $22 \mathrm{~h}$ with $500 \mathrm{U} / \mathrm{mL}$ recombinant human IL-4 (rhIL-4; US-Biological) and $800 \mathrm{U} / \mathrm{mL}$ recombinant human granulocyte-macrophage colony-stimulating factor (rhGM-CSF; Sheering Plough) and then stimulated for $24 \mathrm{~h}$ with $100 \mu \mathrm{g} / \mathrm{mL}$ of GBCCL lysates, TRIMEL (TRIMEL-DCs) or with medium [activated monocytes (AM)] as previously described [20].

\section{DC/T cell co-cultures}

For allogeneic cell co-cultures, $\mathrm{CD}^{+} \mathrm{T}$ cells from healthy donors were sorted with a FACSAria II sorter (BD Biosciences) and co-cultured for 5 days with TRIMEL-DCs or DCs matured with GBCCL lysates at a 20:1 ratio in RPMI 1640 medium supplemented with $10 \%$ FBS and 150 UI/ $\mathrm{mL}$ rhIL-2 (Proleukin). For autologous co-cultures, sorted $\mathrm{CD}^{+}{ }^{+} \mathrm{T}$ cells from HLA-A2 ${ }^{+}$healthy donors were co-cultured with AM, TRIMEL-DCs or DCs matured with the M2 lysate (M2-DCs) for 14 days at a 10:1 ratio in RPMI 1640 medium supplemented with $10 \%$ FBS and $150 \mathrm{UI} / \mathrm{mL}$ rhIL2. T cells were re-stimulated at day 7 with freshly prepared DCs maintaining the cell:cell ratio. Surface expression of CD25, CD69, CXCR3 and CXCR4 was analyzed in CD4 ${ }^{+}$ and $\mathrm{CD} 8^{+} \mathrm{T}$ cells by flow cytometry. For intracellular IFN- $\gamma$, TNF- $\alpha$ and IL- 4 staining, $1 \times 10^{6} \mathrm{~T}$ cells were cultured for $4 \mathrm{~h}$ at $37^{\circ} \mathrm{C}$ in RPMI 1640 medium with $10 \%$ FBS containing $1 \mu \mathrm{g} / \mathrm{mL}$ ionomycin, $0.15 \mu \mathrm{M}$ phorbol myristate acetate (PMA), and $3 \mu \mathrm{g} / \mathrm{mL}$ brefeldin A. T cell proliferation was studied using carboxyfluorescein succinimidyl ester (CFSE) dilution analysis.

\section{IFN-p ELISpot}

Autologous $\mathrm{CD}^{+} \mathrm{T}$ cells activated with AM, TRIMEL-DCs or M2-DCs were sorted and co-cultured with $1 \times 10^{4}$ target cells: HLA-A2 ${ }^{+}$GBCCL (GBd1, TGBC-2TKB, CAVE), HLA-A2 ${ }^{+}$melanoma cell line (Mel1) or K562 for $16 \mathrm{~h}$ at different effector/target ratios. IFN- $\gamma$ release was tested by an ELISpot assay according to the manufacturer's instructions (ELISPOT Ready-SET-Go, eBioscience) as previously described [20].

\section{Statistical analysis}

Statistical analysis was achieved using GraphPad Prism software version 6.0 (GraphPad Software, San Diego, CA, USA). Student's $t$ test was used to determine differences between treatments and results are presented as mean \pm standard deviation (SD). $p$ values $<0.05$ were considered significant.

\section{Results}

\section{GBCCL express relevant tumor-associated antigens present in GBC tissues}

To select a GBCCL suitable for the production of cell lysates as a source of multiple tumor antigens, the levels of expression of 10 of the most common and relevant TAAs (survivin, MUC-1, CEA, erbB2, CA19-9, MAGE-1, MAGE- 2, MAGE-3, GAGE-1/2 and BAGE) were determined in eight publicly available GBCCL (GBd1, G415, OCUG-1, NOZ, $1 \mathrm{TKB}, 2 \mathrm{TKB}, 14 \mathrm{TKB}$ and 24TKB) and in one GBCCL established in our lab (CAVE). The protein levels of survivin, MUC-1, CEA, erbB2 and CA19-9 were determined by flow cytometry, whereas the expression of MAGEs, GAGEs and BAGE was evaluated at the RNA level by RT-PCR. The nine GBCCL showed diverse levels and patterns of antigen expression and none of them expressed all ten antigens, but all expressed at least two of them (Fig. 1a-c). The expression of erbB2 was detected in all the cell lines analyzed, whereas the 2TKB cells expressed only the antigens GAGE1/2 and BAGE. The cell lines with the broader pattern of antigen expression were $2 \mathrm{TKB}$ and 1TKB, which express 8 and 7 of the 10 antigens, respectively (Fig. 1c). Additionally, survivin, MUC-1, CEA, erbB2 and CA19-9 antigens were also detected in a significant number of tumor samples from GBC patients (Fig. 1d), suggesting that these were suitable antigen targets for immunotherapy approaches.

\section{Heat shock induces the production of DAMPs in GBCCL}

For the last 15 years, we have been developing a DC-based immunotherapy that improves the long-term survival of patients with advanced melanoma [11]. In our approach, a lysate derived from a mix of three heat shock-conditioned allogeneic melanoma cells (Mel1, Mel2, and Mel3), named TRIMEL, has been used as a source of both TAAs and DAMPs. Heat shock-induced DAMPs, particularly plasma 

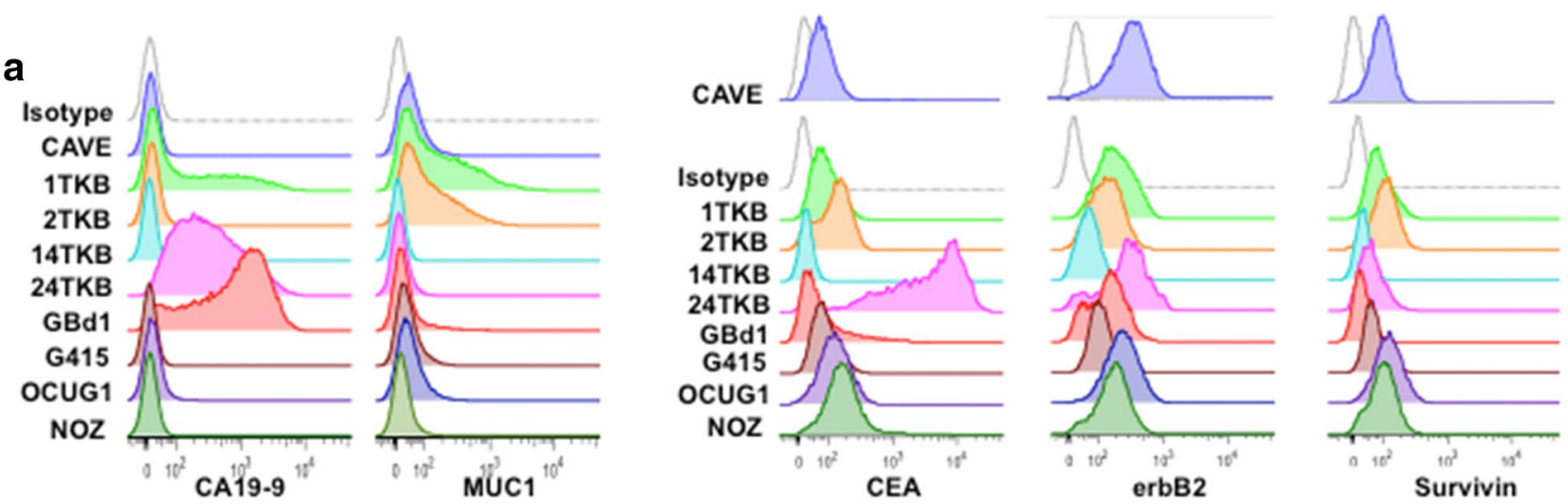

b

C
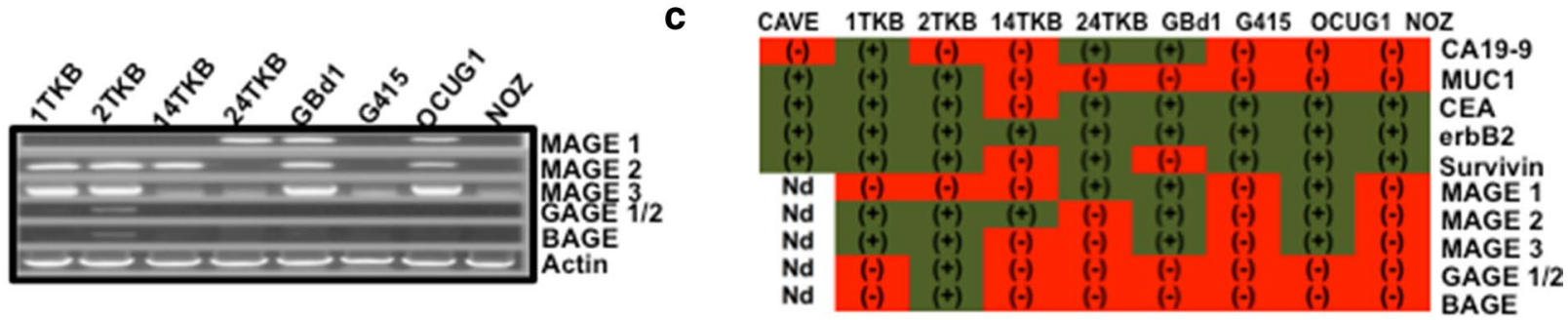

d

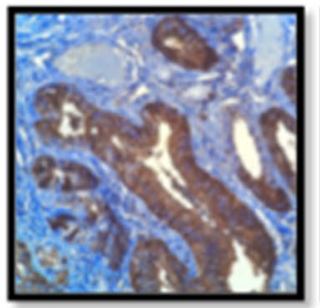

CA19-9

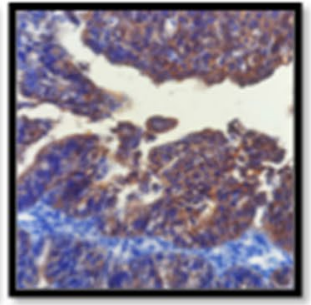

MUC1

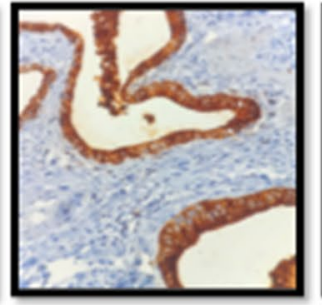

CEA

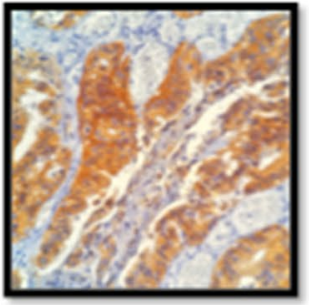

erbB2

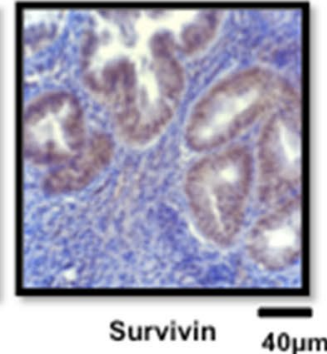

Fig. 1 Tumor associated antigen expression in GBCCL and GBC fresh tumor samples. a Representative histograms for CA19-9, MUC1, CEA, erbB2 and survivin expression in GBCCL evaluated by flow cytometry. Grey histograms indicate isotype control staining. b mRNA expression profiles for MAGE 1, 2, 3, GAGE 1/2 and BAGE in the GBCCL analyzed by RT-PCR. Actin was used as a housekeep-

membrane translocated eCRT and released HMGB 1, mediate an optimal antigen presenting cell (APC) maturation and antigen cross-presentation, providing a unique strategy to obtain efficient tumor antigen-presenting cells with a mature DC-like phenotype [13].

Here, we evaluated the production of three common DAMPs (released HMGB 1 and ATP, and translocated eCRT) in GBCCL subjected to heat shock. Heat shock treatment induced HMGB1 and ATP release in four of the eight cell lines evaluated (14TKB, G415, GBd1 and NOZ for ATP; and 2TKB, 24TKB, G415 and OCUG1 for HMGB1) (Fig. 2a, b). Additionally, three GBCCL translocated eCRT to the plasma membrane in response to heat shock (2TKB, GBd1 and OCUG1) (Fig. 2c, d). The levels of heat shockinduced DAMPs in GBCCL were similar that those induced ing gene control. c Summary of tumor associated antigen expression in GBCCL. Green and red refers to positive or negative expression, respectively. $N D$ not determined. d Representative photomicrographs of immunohistochemical staining for CA19-9, MUC-1, CEA, erbB2 and survivin in paraffin-embedded tumor biopsies obtained from Chilean GBC patients (scale bar, $40 \mu \mathrm{m}$ )

in the melanoma cell lines Mel1, Mel2 and Mel3, which were used as positive controls.

\section{Heat shock-conditioned GBCCL lysate mixtures, but not lysates from individual cell lines, induce differentiation of activated monocytes into mature DCs}

As previously reported $[13,20]$, the addition of TRIMEL to IL-4/GM-CSF-activated monocytes (AM) mediated up to threefold induction of surface markers associated with DC maturation such as HLA-DR, CD80 and CD86 (Fig. 3a). However, heat shock-conditioned lysates prepared from each of the GBCCL did not induce a significant increase in the expression of these markers in stimulated AM (Fig. 3a). 

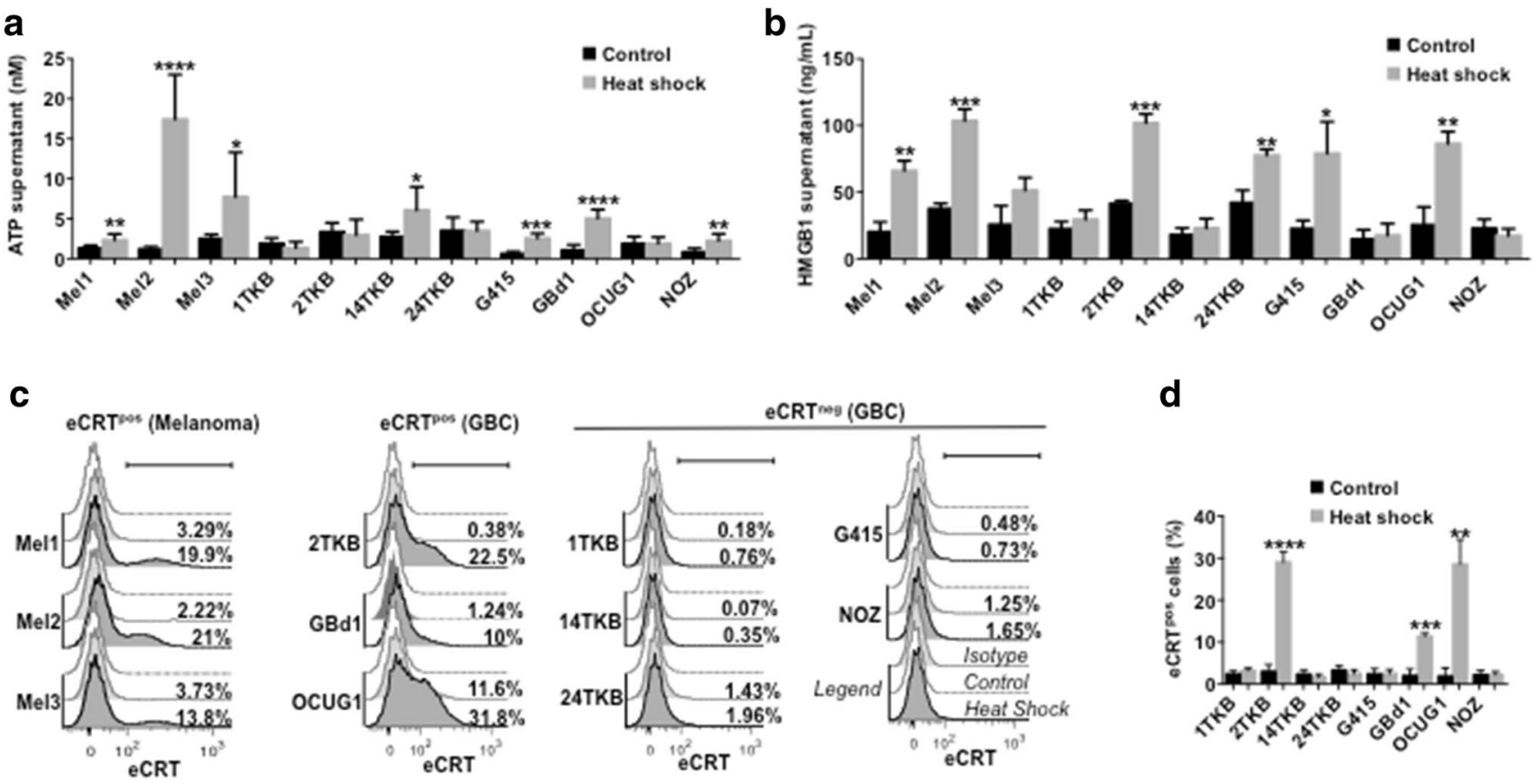

eCRT ${ }^{\infty}(\mathbf{G B C})$

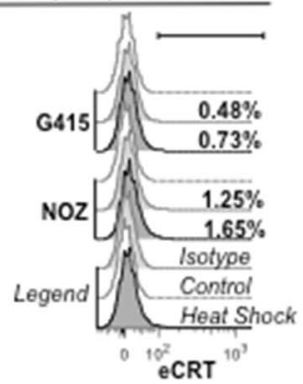

d

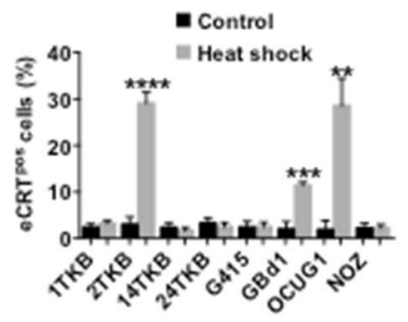

Fig. 2 Heat shock conditioning induces DAMP production in GBCCL. The levels of ATP (a) or HMGB1 (b) were evaluated in the supernatants from heat shock-treated or control cells. c Representative histograms showing the extracellular expression levels of translocated calreticulin (eCRT) in heat shock-treated (dark grey) or control (light grey) melanoma and GBC cells. White histograms indicate isotype control staining. The percentage of eCRT positive (eCRT ${ }^{\text {pos }}$ ) for each condition is shown. d Statistical analysis of eCRT translocation induced by heat shock in GBCCL. Bars represent averages and standard deviations of three (b-d) or five-seven (a) measurements of three independent experiments. ${ }^{*} p<0.05 ;{ }^{* *} p<0.01 ; * * * p<0.001$; $* * * * p<0.0001$

with the GBCCL lysates M2, M3, M5 and M8 (named M2-DCs, M3-DCs, M5-DCs and M8-DCs, respectively) or with TRIMEL (TRIMEL-DCs, as a positive control) to activate allogeneic $\mathrm{T}$ cells. After 5 days of DC/T cell cocultures, we evaluated the surface expression of the lymphocyte activation markers CD25 and CD69 and the chemokine receptors CXCR3 and CXCR4 on $\mathrm{CD}^{+}{ }^{+}$and $\mathrm{CD} 8^{+} \mathrm{T}$ cells. All the DCs tested induced increased levels of CD25 and CD69 in both subsets (Fig. 4a). Moreover, all DCs were able to induce the expression of both receptors CXCR3 and CXCR4 in $\mathrm{CD}^{+}{ }^{+} \mathrm{T}$ cells (Fig. $4 \mathrm{a}$ ) whereas only the chemokine receptor $\mathrm{CXCR} 3$ was induced in $\mathrm{CD}^{+} \mathrm{T}$ cells co-cultured with all the DC types (Fig. 4a). Additionally, our results demonstrated that both $\mathrm{CD}^{+}{ }^{+}$and $\mathrm{CD} 8^{+} \mathrm{T}$ cells co-cultured with allogeneic DCs loaded with GBCCL heat shock-conditioned lysates expressed high levels of the Th1 cytokines IFN- $\gamma$ and TNF- $\alpha$, whereas co-cultured $\mathrm{CD} 8^{+}$ but not $\mathrm{CD} 4^{+} \mathrm{T}$ cells expressed the $\mathrm{Th} 2$ polarizing cytokine IL-4 (Fig. 4b-d). Finally, all the DCs evaluated induced the proliferation of both $\mathrm{CD}^{+}{ }^{+}$and $\mathrm{CD} 8^{+}$allogeneic $\mathrm{T}$ cells (Fig. 4e).

Based on these results, we selected M2-DCs (loaded with heat shock-conditioned lysate from 2TKB, 24TKB and GBd1 GBCCL) for further experiments. The cell lines composing the M2 lysate were adenocarcinoma cell lines (the 

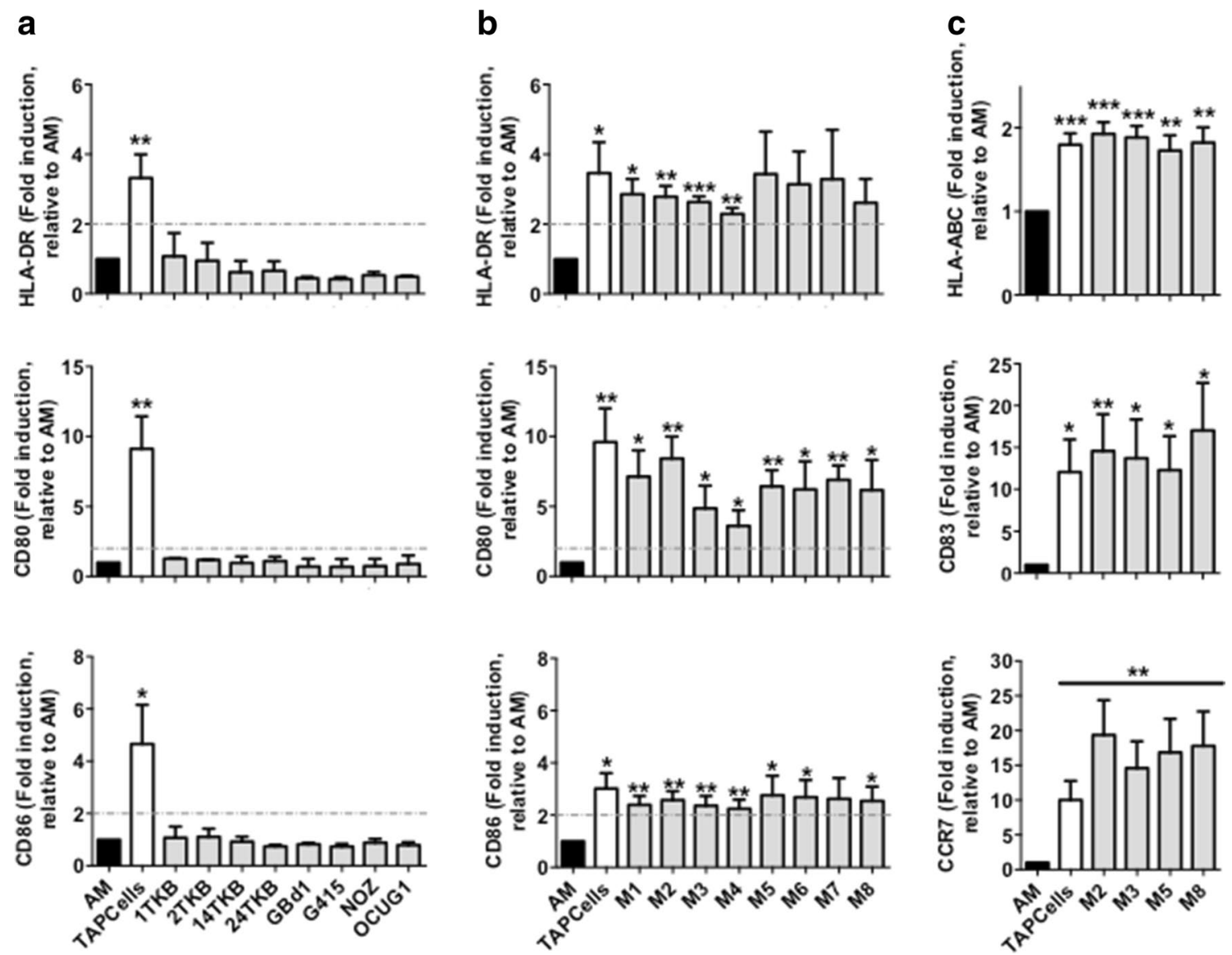

Fig. 3 Heat shock-conditioned GBCCL lysate mixtures, but not lysates from individual cell lines, induce differentiation of activated monocytes into mature DCs. Surface expression of HLA-DR, CD80, CD86 (a, b), and HLA-ABC, CD83, and CCR7 (c) were evaluated by flow cytometry on activated monocytes (AM) incubated or not for $24 \mathrm{~h}$ with $100 \mu \mathrm{g} / \mathrm{mL}$ of heat shock-conditioned tumor lysates generated from individual GBCCL (a) or mixtures (M1-M8) of three different GBCCL $(\mathbf{b}, \mathbf{c})$. Bars represent the average and SD of the fold

most common histology of GBC) and combined they could provide a complete panel of TAAs and DAMPs (Figs. 1c, 2).

\section{T cells activated by autologous $M 2-D C s$ recognize HLA-A2-matched GBCCL}

Given that the heat shock-conditioned M2 lysate potentially contains a large number of GBC tumor-antigenic epitopes for priming $\mathrm{T}$ cell responses, we investigated whether $\mathrm{CD}^{+}$tumor-specific IFN- $\gamma$-secreting T cells were also being elicited in vitro by autologous HLA-A2 ${ }^{+}$ M2-DCs. First we observed that M2-DCs were able to activate autologous $\mathrm{CD} 4^{+}$and $\mathrm{CD} 8^{+} \mathrm{T}$ cells, measured by the percentage of $\mathrm{T}$ cells expressing CD25 and CD69 after 14 days of co-culture (Fig. 5a, b). Then, $\mathrm{CD} 8^{+} \mathrm{T}$ cells were isolated after co-culture by cell-sorting and induction of the integrated MFI (iMFI: \% positive cells $\times$ geoMFI of positive cells) for each marker relative to AM from at least three independent experiments. Evaluated cell lysates mix were made as follows: M1 (24TKB + GBd1 + G415); M2 (2TKB + 24TKB + GBd1); M3 (1TKB + 2TKB + 24TKB); M4 (OCUG1 + GBd1 + G415); M5 (2TKB + G415+ OCUG1); M6 (NOZ+OCUG 1+G415); M7 $(1 \mathrm{TKB}+14 \mathrm{TKB}+24 \mathrm{TKB}) ;$ and M8 (24TKB + OCUG1 + G415). $* p<0.05 ; * * p<0.01 ; * * * p<0.001$

challenged with two HLA-A2 ${ }^{+}$GBCCL present in the M2 lysate (2TKB and GBd1), a HLA-A2 ${ }^{+}$GBCCL that was not included in the M2 lysate (CAVE), a HLA-A2 ${ }^{+}$melanoma cell line (Mel1), or with K562 cells as a negative control. After challenging with $2 \mathrm{TKB}, \mathrm{GBd} 1$ or CAVE cells, M2-DC-activated CD ${ }^{+} \mathrm{T}$ cells released significantly higher levels of IFN- $\gamma$ than $\mathrm{CD} 8^{+} \mathrm{T}$ cells unstimulated or co-cultured with AM or TRIMEL-DCs (Fig. 5c). The NK cell-sensitive cell line K562 did not induce IFN- $\gamma$ release by the activated $\mathrm{CD} 8^{+} \mathrm{T}$ cells. Additionally, we observed that there was an important cross-recognition of melanoma cells by $\mathrm{T}$ cells activated with M2-DCs (Fig. 5c). Similarly, T cells activated with TRIMEL-DCs were able to cross-recognize GBC cells, which may be indicative of shared antigens between both kinds of tumor cells. 

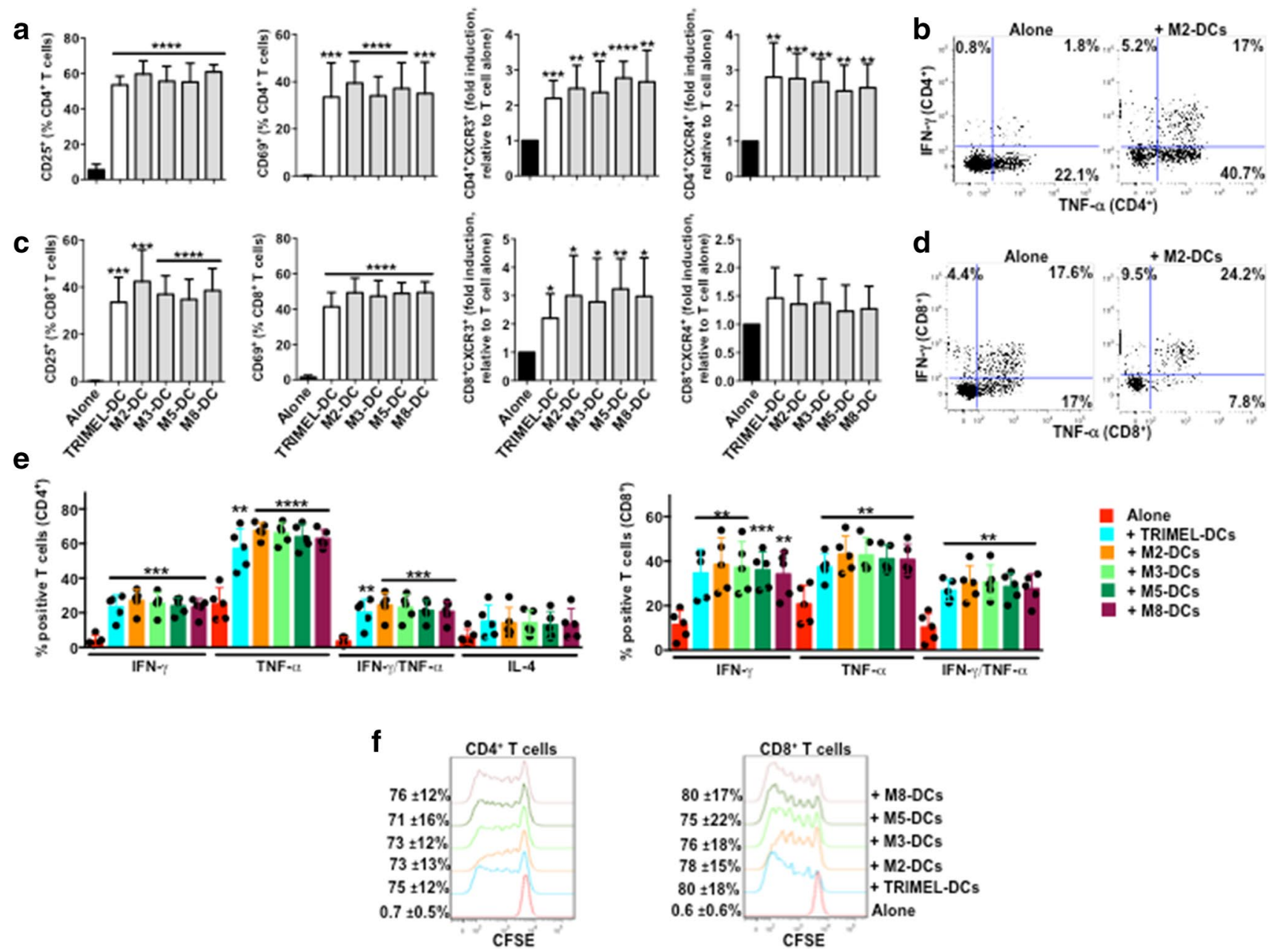

Fig. 4 Activation of allogeneic $\mathrm{T}$ cells by monocyte-derived DCs matured with different heat shock-conditioned GBC lysates. Purified $\mathrm{CD}^{+} \mathrm{T}$ cells were co-cultured for 5 days with allogeneic TRIMEL-, M2-, M3-, M5-, M8-DCs or without DCs. The surface expression of CD25, CD69, CXCR3 and CXCR4 (a), the intracellular levels of IFN- $\gamma$, TNF- $\alpha$ and IL-4 (b-d), and proliferation (e) were evaluated in the $\mathrm{CD}^{+}$and $\mathrm{CD} 8^{+} \mathrm{T}$ cells populations by flow cytometry. a, $\mathbf{d}$ Bars represent the average and SD from five independent experiments of the $\%$ of $\mathrm{T}$ cells positive for each marker, with the excep-

\section{Discussion}

Exploration of new active immunotherapies as complements to the relatively recent approaches grounded on blockade of immune checkpoint molecules, such as cytotoxic T-lymphocyte antigen 4 (CTLA-4), programmed death (PD)-1 and PD-ligand-1 (PD-L1), may constitute a feasible possibility for improvement of clinical response rates. Particularly, DCbased cancer vaccines again become an interesting alternative because of their relative effectiveness in activating cellmediated immune responses and lack of severe side effects in patients [21]. In this context, whole tumor cell lysates are excellent sources for the delivery of a wide range of TAAs

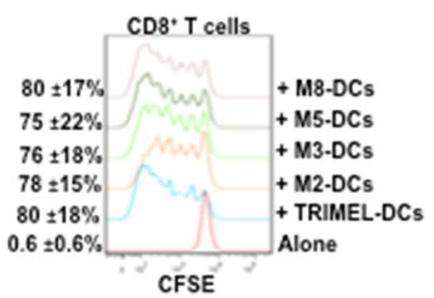

tion of CXCR3 and CXCR4 data that are shown as fold induction of the MFI relative to unstimulated T cells. Representative dot plots of IFN- $\gamma$ and TNF- $\alpha$ production in allogeneic $\mathrm{CD}^{+}(\mathbf{b})$ and $\mathrm{CD}^{+}(\mathbf{c})$ $\mathrm{T}$ cells co-cultured with M2-DCs. e The percentage and SD of proliferating T cells are showed on the left of each histograms. Evaluated cell lysates mix were made as follows: $\mathrm{M} 2(2 \mathrm{TKB}+24 \mathrm{TKB}+\mathrm{GBd} 1)$; M3 (1TKB + 2TKB + 24TKB); M5 (2TKB + G415+ OCUG1); and M8 (24TKB + OCUG1 + G415). * $p<0.05 ; * * p<0.01 ; * * * p<0.001$; $* * * * p<0.0001$ (comparison versus unstimulated T cells)

that will generate MHC class I/II T cell epitopes for inducing the activation of $\mathrm{CD}^{+}{ }^{+}$helper and $\mathrm{CD} 8^{+}$cytotoxic $\mathrm{T}$ cells simultaneously, and therefore, a more integral immune response.

One method to determine the potential usefulness of DC-based immunotherapy in GBC patients is to explore the immunogenicity of GBC tumors by measuring the impact of $\mathrm{T}$ cell subpopulation infiltration at tumor sites and to correlate this with the overall survival of patients. Tumor-infiltrating immune cells constitute an accepted manifestation of the host immune response against cancer. Likewise, a relationship between tumor-infiltrating immune cells and GBC prognosis has been suggested. In fact, recent published data 

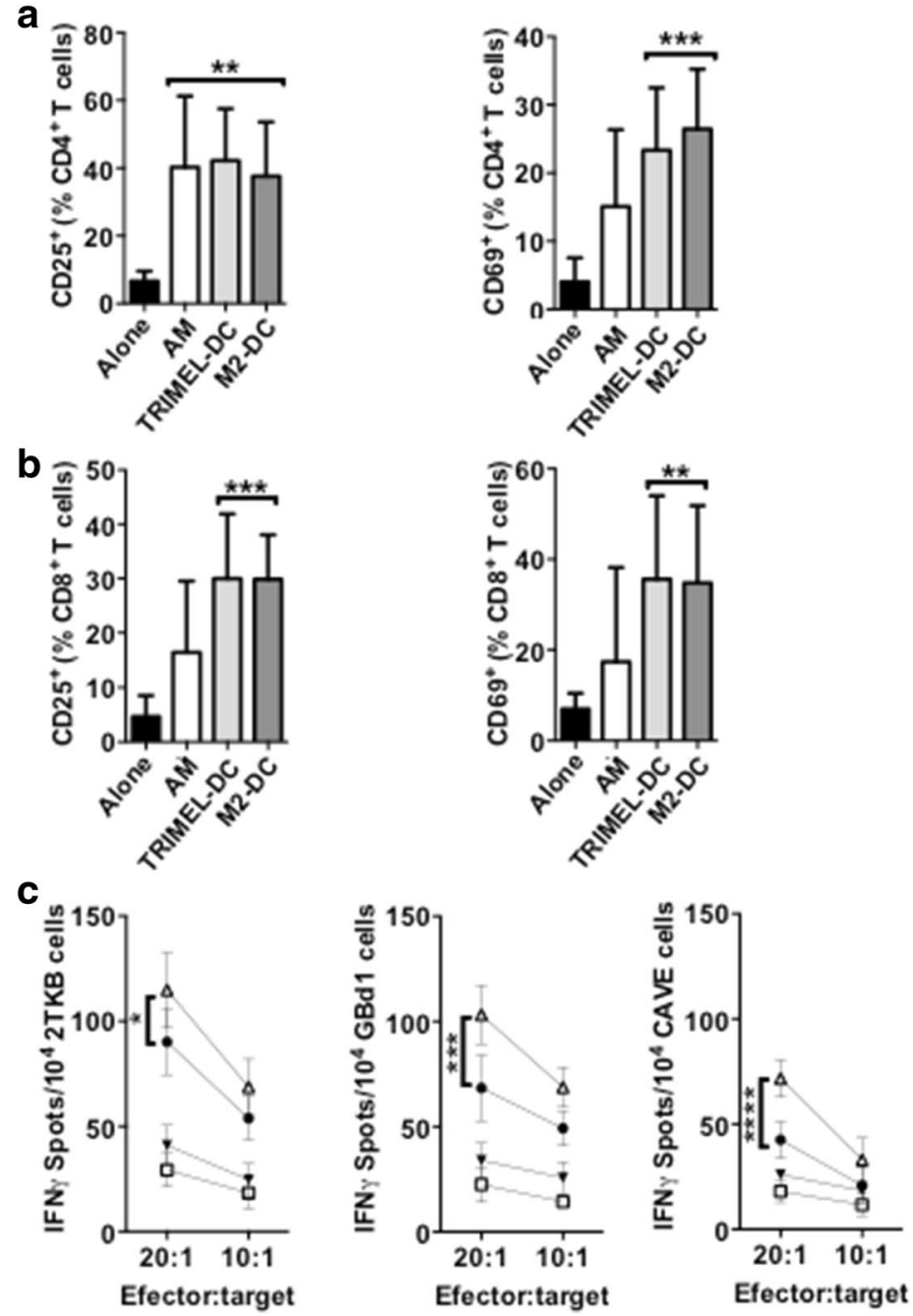
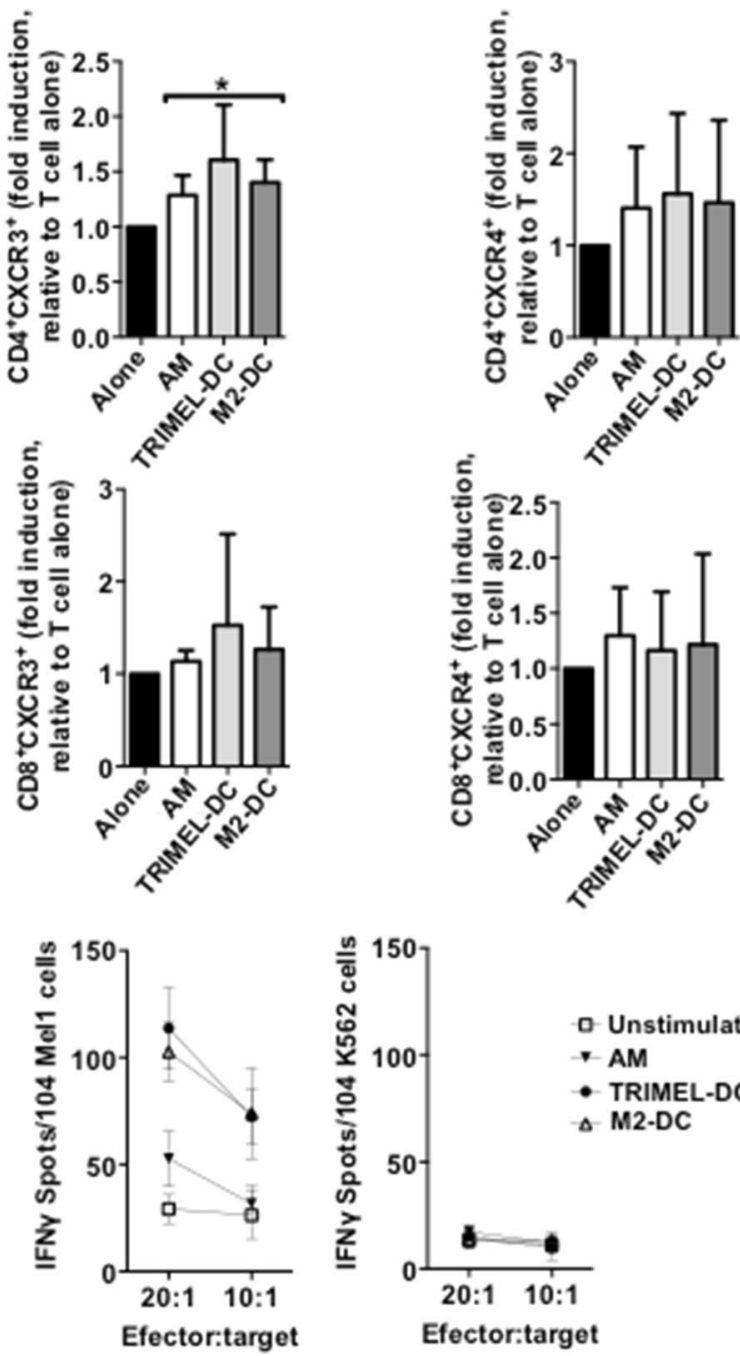

- Unstimulated

$\rightarrow$ AM

- TRIMEL-DC

$\triangle$ M2-DC

Fig. 5 T cells activated by autologous monocyte-derived DCs loaded with a heat shock conditioned GBC lysate recognize HLA-A2matched GBCCL. a-c Purified $\mathrm{CD}^{+} \mathrm{T}$ cells were co-cultured for 14 days with autologous HLA-A2 ${ }^{+}$AM, TRIMEL-DCs, M2-DCs or cultured alone. The surface expression of CD25, CD69, CXCR3 and CXCR4 $(\mathbf{a}, \mathbf{b})$ were evaluated in the $\mathrm{CD}^{+}(\mathbf{a})$ and $\mathrm{CD}^{+}(\mathbf{b}) \mathrm{T}$ cells populations by flow cytometry. Bars represent the average and SD from at least three independent experiments of the \% of T cells positive for each marker, with the exception of CXCR3 and CXCR4 data that are shown as fold induction of the MFI relative to unstimu-

from our and other groups showed that $\mathrm{CD} 8^{+} \mathrm{T}$ cell infiltration at different disease stages correlates with improved survival of GBC patients [22-24]. In one study, in which 45 tumor samples from GBC patients and 65 benign gallbladder tissues were examined, increased frequencies of $\mathrm{CD}^{+}, \mathrm{CD}^{+}{ }^{+} \mathrm{T}$ cells and DCs were observed in GBC samples, which significantly correlated with prolonged patient survival [23]. In a more recent study, Oguro and coworkers [25] analyzed $211 \mathrm{GBC}$ samples and found that a lower density of tumor-infiltrating $\mathrm{CD} 8^{+}$cells and higher ratios between Foxp $3^{+} / \mathrm{CD}^{+}, \mathrm{B}$ and $\mathrm{T}$ lymphocyte attenuator/ lated T cells. $* p<0.05 ; * * p<0.01 ; * * * p<0.001$ (comparison versus unstimulated T cells). c Sorted CD8 ${ }^{+} \mathrm{T}$ cells were challenged for $16 \mathrm{~h}$ with the HLA-A2 ${ }^{+}$GBCCL 2TKB, GBd1, CAVE, the melanoma cell line Mel1 or K562 cells. IFN- $\gamma$ release was measured by ELISPOT at different effector:target ratios as indicated. Data represent the average and SD of at least three independent experiments. $* p<0.05$; $* * * p<0.001 ; * * * * p<0.0001$ (comparison M2-DC versus TRIMELDCs stimulated $\mathrm{T}$ cells). M2 refer to the mixture made from three different GBCCL

$\mathrm{CD}^{+}$, and casitas-B-lineage lymphoma protein-b/CD8 ${ }^{+}$ were significantly associated with shorter overall survival in GBC patients. Moreover, in a cohort of 80 Chilean GBC patients, we observed that a greater infiltration of $\mathrm{CD} 8^{+} \mathrm{T}$ cells in cancer tissue was associated with a favorable prognostic biomarker for both early and advanced stage patients [24]. Altogether, these observations strongly indicate that a natural host $\mathrm{CD} 8^{+} \mathrm{T}$ cell-mediated immune response against $\mathrm{GBC}$ increases patient survival. These findings encourage the design and development of adjuvant immunotherapeutic approaches against GBC. 


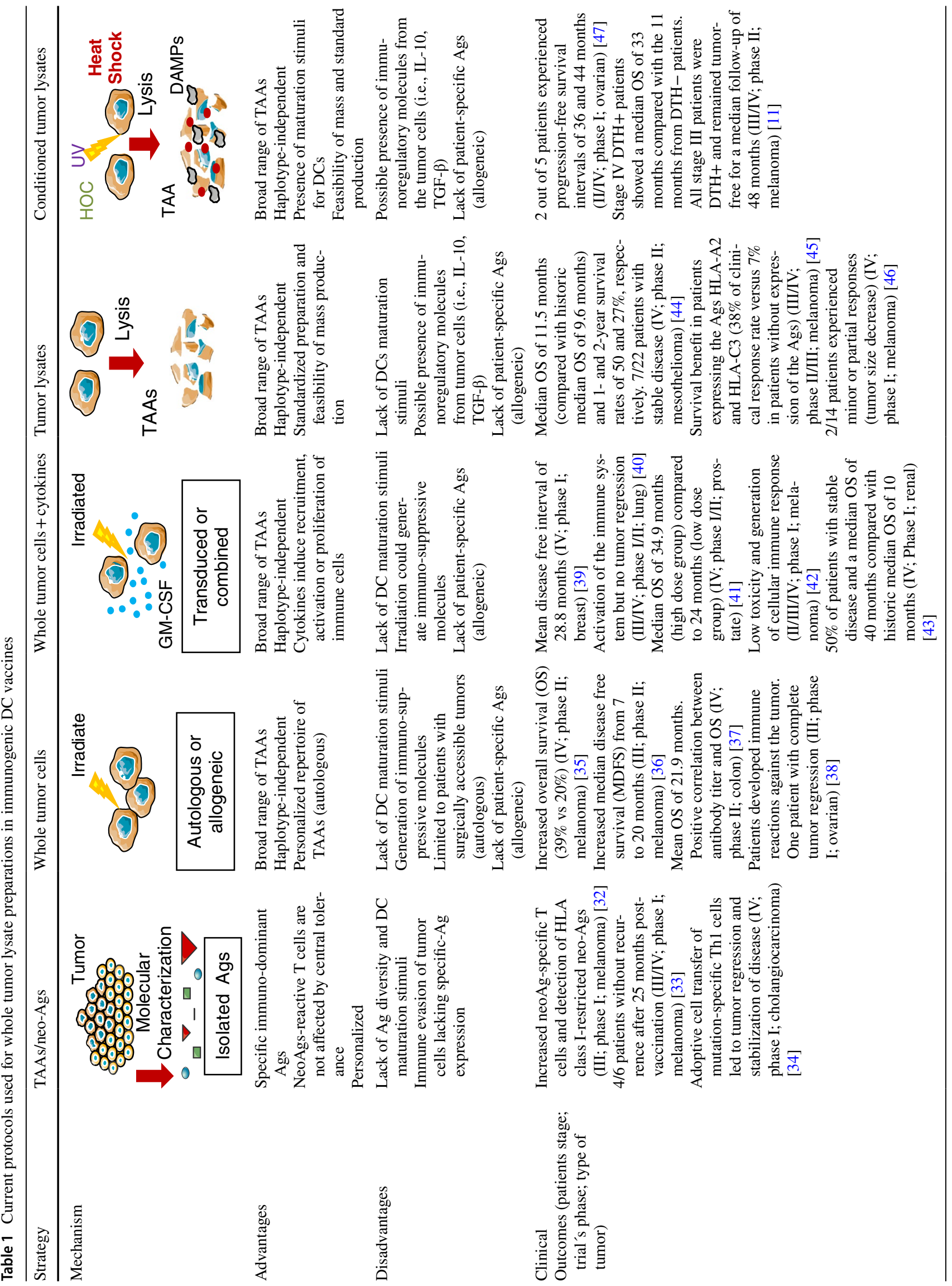


The aforementioned GBC $\mathrm{T}$ cell infiltration might be orchestrated by the chemokine receptor CXCR4, given that its ligand, C-X-C motif ligand-12 (CXCL12), is frequently overexpressed in GBC [26]. Likewise, the expression of CXCR3 by lymphocytes can mediate its migration to GBC tumor beds [27]. These data suggest that the induction of these chemokine receptors in $\mathrm{T}$ cells by therapeutic DCs would be beneficial for the DC-mediated anti-tumor responses in vaccinated patients.

The potential use of immunotherapeutic approaches for GBC has only recently become a subject of intensive investigation. In fact, current immunotherapies against GBC have been focused on the use of peptide-based vaccines or peptide-loaded DCs $[21,28]$. These strategies have shown modest clinical improvements, likely due to induced tolerance by dominant single tumor peptides or by the selection of antigen loss variants in established tumors. In contrast, a study where DC loaded with autologous tumor cell lysates combined with activated $\mathrm{T}$ cell transfer were used as an adjuvant treatment in operated patients with advanced intrahepatic cholangiocarcinoma, reported improved post-operative progression-free and overall survival compared to patients receiving surgery alone [29].

The optimal delivery of tumor antigens is one of the most important factors for the success of DC-based anti-cancer vaccines. With this in mind, lysates from allogeneic tumor cells, whole tumor cells, tumor mRNA, and antigenic peptides, have all been tested as tumor vaccines. Autologous whole tumor antigens offer an unparalleled advantage as it allows DCs to process and present a broad range of TAAs to stimulate strong, polyclonal and long-term memory $\mathrm{CD}^{+}$and $\mathrm{CD} 8^{+} \mathrm{T}$ cell responses, potentially preventing tumor immune escape. Moreover, this strategy is suitable for all cancer patients regardless of their HLA haplotype. However, not all cancer patients have surgically removable tumors, and therefore, a useful and promising alternative is the preparation of allogeneic cancer cell lysates that have demonstrated to provide a standardized applicable source of tumor-specific antigens in patients with non-resectable tumors [30]. Importantly, the method used for inducing cell death or protein chemical modifications during whole tumor lysate preparation could impact the immunogenicity and efficacy of the therapy (Table 1). Current immunogenic treatment modalities used for pre-conditioning tumor cell lysates include ultraviolet irradiation, oxidation-inducing modalities and heat shock treatments [31]. In the present study, we generated heat shock-conditioned tumor lysate for GBC (M2), which have some important characteristics that suggest its potential as an antigen source for DC vaccines: (1) it contains a broad panel of TAAs, also expressed in tumors from GBC patients, (2) it includes different molecules that could act as DAMPs (released HMGB1, ATP and eCRT), (3) it promotes a rapid and efficient differentiation of monocytes to mature DCs, and (4) DCs generated with this lysate are able to induce the activation of $\mathrm{T}$ cells that specifically recognize tumor cells.

In general, in vivo tumor antigen presentation by immunotherapeutic DCs might drive the development of tumorspecific adaptive immune responses, whereas cytotoxic $\mathrm{CD} 8^{+} \mathrm{T}$ cells recognize and attack tumor cells through recognition of TAA peptides associated to MHC class I. Therefore, T-cell cytotoxicity depends on MHC class I expression on tumor cell surface. It has been frequently observed that tumor cells lost MHC class I expression, and therefore, the efficacy of DC-mediated immunotherapies may be reduced. In line with this hypothesis, it has been shown that reduced MHC class I expression in biliary tract cancers, including GBC, was linked to shortened overall patient survival [48]. However, in the majority of cases the loss of MHC class I is partial, affecting only some isotypes, and thus an important portion of cancer patients could benefit from DC-mediated immunotherapy. Moreover, it is very important to incorporate strategies to recover MHC class I expression in tumors to improve immunotherapy effect [49]. In conclusion, we propose that GBC cell lysate-loaded DCs may be considered for future immunotherapy approaches alone or in combination with currently used immune checkpoint moleculeblocking therapies.

Acknowledgements We thank Marisol Briones for administrative and technical support, and Benedict Chambers for critical reading and English editing of the manuscript.

Author contributions DR-S contributed to the experimental design and conducted most of the experiments shown in this paper; IG and JMB contributed to the collection of tumor biopsies; JCR contributed to the establishment of the different GBCCLs; DR-S, IG and AT contributed to the statistical analysis conducted in this paper; FS-O designed and coordinated the study; DR-S, AT, MAG, IÁ, CP, FEG, PF, MNL and FS-O analyzed the data and wrote the manuscript. All authors had full access to all reported data and take responsibility for the integrity of the data and the accuracy of the data analysis. All authors take responsibility for the preparation of the manuscript.

Funding This work was supported by grants from the National Fund for Scientific and Technological Development (FONDECYT) 1171213 and 11160380; the Fund for the Promotion of Scientific and Technological Development (FONDEF) ID16i10148; Millennium Institute on Immunology and Immunotherapy (MIII) P09/016-F; National Commission for Scientific and Technological Research (CONICYT)-PCHA/ Doctorado Nacional/21130465; CONICYT-PAI/TESIS DOCTORADO SECTOR PRODUCTIVO/7815110008; FONDECYT POSTDOCTORADO 3170917.

\section{Compliance with ethical standards}

Conflict of interest The authors declare that they have no conflict of interest.

Ethical approval and ethical standards The use of paraffin embedded GBC tissue of the patients was approved by the bioethical committee 
of the Hospital Clínico of the Universidad de Chile (Approval act 75), which authorize the use of biopsies under the supervision of the director of the Pathological Anatomy Service (Dr. Iván Gallegos). Informed consent from patients was not required for this work, given that it corresponds to a retrospective study. The Bioethical Committee of the Centro Metropolitano de Sangre y Tejidos, Hospital Metropolitano (Santiago de Chile) approved the use of buffy coats from healthy donors.

Open Access This article is distributed under the terms of the Creative Commons Attribution 4.0 International License (http://creativeco mmons.org/licenses/by/4.0/), which permits unrestricted use, distribution, and reproduction in any medium, provided you give appropriate credit to the original author(s) and the source, provide a link to the Creative Commons license, and indicate if changes were made.

\section{References}

1. Rojas-Sepúlveda D, Gleisner MA, Pereda C, López MN, SalazarOnfray F (2016) Tumor cell lysates as maturation stimulus and antigen source for therapeutic dendritic cells against gallbladder cancer. Eur J Immunol 46(S1):1221-1222 (poster)

2. Rojas-Sepúlveda D, Gleisner MA, Pereda C, López MN, Salazar-Onfray F (2017) Tumor lysate loaded dendritic cells induce a $\mathrm{T}$ cell specific antitumor response against gallbladder cancer. $\mathrm{J}$ Immunol 198(1 Supplement):79.18 (poster)

3. Guida M, Pisconte S, Colucci G (2012) Metastatic melanoma: the new era of targeted therapy. Expert Opin Ther Targets 16 Suppl 2:S61-S70. https://doi.org/10.1517/14728222.2011.645807

4. Larkin J, Chiarion-Sileni V, Gonzalez R, Grob JJ, Cowey CL, Lao CD et al (2015) Combined nivolumab and ipilimumab or monotherapy in untreated melanoma. N Engl J Med 373:23-34. https://doi.org/10.1056/NEJMoa1504030

5. Farolfi A, Ridolfi L, Guidoboni M, Nicoletti SV, Piciucchi S, Valmorri L et al (2012) Ipilimumab in advanced melanoma: reports of long-lasting responses. Melanoma Res 22:263-270. https://doi. org/10.1097/CMR.0b013e328353e65c

6. Brahmer JR, Drake CG, Wollner I, Powderly JD, Picus J, Sharfman WH et al (2010) Phase I study of single-agent antiprogrammed death-1 (MDX-1106) in refractory solid tumors: safety, clinical activity, pharmacodynamics, and immunologic correlates. J Clin Oncol 28:3167-3175. https://doi.org/10.1200/ JCO.2009.26.7609

7. Simeone E, Ascierto PA (2012) Immunomodulating antibodies in the treatment of metastatic melanoma: the experience with antiCTLA-4, anti-CD137, and anti-PD1. J Immunotoxicol 9:241-247. https://doi.org/10.3109/1547691X.2012.678021

8. Hamid O, Robert C, Daud A, Hodi FS, Hwu WJ, Kefford R et al (2013) Safety and tumor responses with lambrolizumab (antiPD-1) in melanoma. N Engl J Med 369:134-144. https://doi. org/10.1056/NEJMoa1305133

9. Kyi C, Postow MA (2016) Immune checkpoint inhibitor combinations in solid tumors: opportunities and challenges. Immunotherapy 8(7):821-837. https://doi.org/10.2217/imt-2016-0002

10. Andrews DM, Maraskovsky E, Smyth MJ (2008) Cancer vaccines for established cancer: how to make them better? Immunol Rev 222:242-255. https://doi.org/10.1111/j.1600-065X.2008.00612.x

11. López MN, Pereda C, Segal G, Muñoz L, Aguilera R, González FE et al (2009) Prolonged survival of dendritic cell-vaccinated melanoma patients correlates with tumor-specific delayed type IV hypersensitivity response and reduction of tumor growth factor beta-expressing T cells. J Clin Oncol 27(6):945-952. https://doi. org/10.1200/JCO.2008.18.0794
12. González FE, Gleisner A, Falcón-Beas F, Osorio F, López MN, Salazar-Onfray F (2014) Tumor cell lysates as immunogenic sources for cancer vaccine design. Hum Vaccin Immunother 10(11):3261-3269. https://doi.org/10.4161/21645515.2014.98299 6

13. Aguilera R, Saffie C, Tittarelli A, González FE, Ramírez M, Reyes D et al (2011) Heat-shock induction of tumor-derived danger signals mediates rapid monocyte differentiation into clinically effective dendritic cells. Clin Cancer Res 17(8):2474-2483. https://doi. org/10.1158/1078-0432.CCR-10-2384

14. Hundal R, Shaffer EA (2014) Gallbladder cancer: epidemiology and outcome. Clin Epidemiol 6:99-109. https://doi.org/10.2147/ CLEP.S37357

15. Ferlay J, Soerjomataram I, Dikshit R, Eser S, Mathers C, Rebelo M, Parkin DM, Forman D, Bray F (2015) Cancer incidence and mortality worldwide: sources, methods and major patterns in GLOBOCAN 2012. Int J Cancer 136(5):E359-E386. https://doi. org/10.1002/ijc. 29210

16. Roa I, Ibacache G, Muñoz S, de Aretxabala X (2014) Gallbladder cancer in Chile: pathologic characteristics of survival and prognostic factors: analysis of 1,366 cases. Am J Clin Pathol 141(5):675-682. https://doi.org/10.1309/AJCPQT3ELN2BBCKA

17. Roa I, de Aretxabala X (2015) Gallbladder cancer in Chile: what have we learned? Curr Opin Gastroenterol 31(3):269-275. https ://doi.org/10.1097/MOG.0000000000000164

18. Smok G, Cervilla K, Bosch H, Csendes A (1986) Precancerous lesions of invasive carcinoma of the gallbladder. Rev Med Chil 114(10):954-958

19. Sheth S, Bedford A, Chopra S (2000) Primary gallbladder cancer: recognition of risk factors and the role of prophylactic cholecystectomy. Am J Gastroenterol 95(6):1402-1410. https://doi.org/1 0.1111/j.1572-0241.2000.02070.x

20. Escobar A, López M, Serrano A, Ramirez M, Pérez C, Aguirre A, González R, Alfaro J, Larrondo M, Fodor M, Ferrada C, SalazarOnfray F (2005) Dendritic cell immunizations alone or combined with low doses of interleukin-2 induce specific immune responses in melanoma patients. Clin Exp Immunol 142(3):555-568. https ://doi.org/10.1111/j.1365-2249.2005.02948.x

21. Marks EI, Yee NS (2016) Molecular genetics and targeted therapeutics in biliary tract carcinoma. World J Gastroenterol 22(4):1335-1347. https://doi.org/10.3748/wjg.v22.i4.1335

22. Goeppert B, Frauenschuh L, Zucknick M, Stenzinger A, Andrulis M, Klauschen F et al (2013) Prognostic impact of tumourinfiltrating immune cells on biliary tract cancer. Br J Cancer 109(10):2665-2674. https://doi.org/10.1038/bjc.2013.610

23. Nakakubo Y, Miyamoto M, Cho Y, Hida Y, Oshikiri T, Suzuoki M, Hiraoka K, Itoh T, Kondo S, Katoh H (2003) Clinical significance of immune cell infiltration within gallbladder cancer. Br J Cancer 89(9):1736-1742. https://doi.org/10.1038/sj.bjc.6601331

24. Fluxá P, Rojas-Sepúlveda D, Gleisner MA, Tittarelli A, Villegas P, Tapia L et al (2018) High CD8(+) and absence of Foxp3(+) $\mathrm{T}$ lymphocytes infiltration in gallbladder tumors correlate with prolonged patients survival. BMC Cancer 18(1):243. https://doi. org/10.1186/s12885-018-4147-6

25. Oguro S, Ino Y, Shimada K, Hatanaka Y, Matsuno Y, Esaki M et al (2015) Clinical significance of tumor-infiltrating immune cells focusing on BTLA and Cbl-b in patients with gallbladder cancer. Cancer Sci 106(12):1750-1760. https://doi.org/10.1111/ cas. 12825

26. Lee HJ, Lee K, Lee DG, Bae KH, Kim JS, Liang ZL et al (2012) Chemokine (C-X-C motif) ligand 12 is associated with gallbladder carcinoma progression and is a novel independent poor prognostic factor. Clin Cancer Res 18(12):3270-3280. https://doi. org/10.1158/1078-0432.CCR-11-2417

27. Patil RS, Shah SU, Shrikhande SV, Goel M, Dikshit RP, Chiplunkar SV (2016) IL17 producing $\gamma \delta T$ cells induce 
angiogenesis and are associated with poor survival in gallbladder cancer patients. Int J Cancer 139(4):869-881. https://doi. org/10.1002/ijc.30134

28. Chai Y (2016) Immunotherapy of biliary tract cancer. Tumour Biol 37(3):2817-2821. https://doi.org/10.1007/s13277-015-4743-X

29. Shimizu K, Kotera Y, Aruga A, Takeshita N, Takasaki K, Yamamoto M (2012) Clinical utilization of postoperative dendritic cell vaccine plus activated T-cell transfer in patients with intrahepatic cholangiocarcinoma. J Hepatobiliary Pancreat Sci 19(2):171-178. https://doi.org/10.1007/s00534-011-0437-y

30. Chiang CL, Coukos G, Kandalaft LE (2015) Whole tumor antigen vaccines: where are we? Vaccines (Basel) 3(2):344-372. https:// doi.org/10.3390/vaccines3020344

31. Vandenberk L, Belmans J, Van Woensel M, Riva M, Van Gool SW (2016) Exploiting the immunogenic potential of cancer cells for improved dendritic cell vaccines. Front Immunol. https://doi. org/10.3389/fimmu.2015.00663

32. Carreno BM, Magrini V, Becker-Hapak M, Kaabinejadian S, Hundal J, Petti AA et al (2015) Cancer immunotherapy. A dendritic cell vaccine increases the breadth and diversity of melanoma neoantigen-specific T cells. Science 348(6236):803-808. https:// doi.org/10.1126/science.aaa3828

33. Ott PA, Hu Z, Keskin DB, Shukla SA, Sun J, Bozym DJ et al (2017) An immunogenic personal neoantigen vaccine for patients with melanoma. Nature 547(7662):217-221. https://doi. org/10.1038/nature22991

34. Tran E, Turcotte S, Gros A, Robbins PF, Lu YC, Dudley ME, Parkhurst MR (2014) Cancer immunotherapy based on mutationspecific CD4+ T cells in a patient with epithelial cancer. Science 344(6184):641-645. https://doi.org/10.1126/science.1251102

35. Hsueh EC, Essner R, Foshag LJ, Ollila DW, Gammon G, O'Day SJ, Boasberg PD, Stern SL, Ye X, Morton DL (2002) Prolonged survival after complete resection of disseminated melanoma and active immunotherapy with a therapeutic cancer vaccine. J Clin Oncol 20(23):4549-4554. https://doi.org/10.1200/ JCO.2002.01.151

36. Mordoh J, Kairiyama C, Bover L, Solarolo E (1997) Allogeneic cells vaccine increases disease-free survival in stage III melanoma patients. A non randomized phase II study. Medicina (Buenos Aires) 57(4):421-427

37. Habal N, Gupta RK, Bilchik AJ, Yee R, Leopoldo Z, Ye W, Elashoff RM, Morton DL (2001) CancerVax, an allogeneic tumor cell vaccine, induces specific humoral and cellular immune responses in advanced colon cancer. Ann Surg Oncol $8(5): 389-401$

38. Berd D (2001) Autologous, hapten-modified vaccine as a treatment for human cancers. Vaccine 19(17):2565-2570. https://doi. org/10.1016/S0264-410X(00)00490-4

39. Emens LA, Asquith JM, Leatherman JM, Kobrin BJ, Petrik S, Laiko M, Stearns V (2009) Timed sequential treatment with cyclophosphamide, doxorubicin, and an allogeneic granulocytemacrophage colony-stimulating factor-secreting breast tumor vaccine: a chemotherapy dose-ranging factorial study of safety and immune activation. J Clin Oncol 27(35):5911-5918. https:// doi.org/10.1200/JCO.2009.23.3494

40. Nemunaitis J, Jahan T, Ross H, Sterman D, Richards D, Fox B, Jablons D, Aimi J, Lin A, Hege K (2006) Phase 1/2 trial of autologous tumor mixed with an allogeneic GVAX vaccine in advanced-stage non-small-cell lung cancer. Cancer Gene Ther 13(6):555-562. https://doi.org/10.1038/sj.cgt.7700922

41. Small EJ, Sacks N, Nemunaitis J, Urba WJ, Dula E, Centeno AS et al (2007) Granulocyte macrophage colony-stimulating factor-secreting allogeneic cellular immunotherapy for hormonerefractory prostate cancer. Clin Cancer Res 13(13):3883-3891. https://doi.org/10.1158/1078-0432.CCR-06-2937

42. Barrio MM, de Motta PT, Kaplan J, von Euw EM, Bravo AI, Chacón RD, Mordoh J (2006) A phase I study of an allogeneic cell vaccine (VACCIMEL) with GM-CSF in melanoma patients. J Immunother 29(4):444-454. https://doi.org/10.1097/01.cji.00002 $08258.79005 .5 \mathrm{f}$

43. Westermann J, Flörcken A, Willimsky G, van Lessen A, Kopp J, Takvorian A et al (2011) Allogeneic gene-modified tumor cells (RCC-26/IL-7/CD80) as a vaccine in patients with metastatic renal cell cancer: a clinical phase-I study. Gene Ther 18(4):354363. https://doi.org/10.1038/gt.2010.143

44. Powell A, Creaney J, Broomfield S, Van Bruggen I, Robinson B (2006) Recombinant GM-CSF plus autologous tumor cells as a vaccine for patients with mesothelioma. Lung Cancer 52(2):189197. https://doi.org/10.1016/j.lungcan.2006.01.007

45. Sondak VK, Sosman JA (2003) Results of clinical trials with an allogeneic melanoma tumor cell lysate vaccine: Melacine. Semin Cancer Biol 13(6):409-415. https://doi.org/10.1016/j.semca ncer.2003.09.004

46. Chang AE, Redman BG, Whitfield JR, Nickoloff BJ, Braun TM, Lee PP, Mulé JJ (2002) A phase I trial of tumor lysate-pulsed dendritic cells in the treatment of advanced cancer. Clin Cancer Res 8(4):1021-1032

47. Chiang CL, Kandalaft LE, Tanyi J, Hagemann AR, Motz GT, Svoronos $\mathrm{N}$ et al (2013) A dendritic cell vaccine pulsed with autologous hypochlorous acid-oxidized ovarian cancer lysate primes effective broad antitumor immunity: from bench to bedside. Clin Cancer Res 19(17):4801-4815. https://doi.org/10.1158/10780432.CCR-13-1185

48. Goeppert B, Frauenschuh L, Zucknick M, Roessler S, Mehrabi A, Hafezi M, Stenzinger A, Warth A, Pathil A, Renner M, Schirmacher P, Weichert W (2015) Major histocompatibility complex class I expression impacts on patient survival and type and density of immune cells in biliary tract cancer. Br J Cancer 113(9):13431349. https://doi.org/10.1038/bjc.2015.337

49. Garrido F, Aptsiauri N, Doorduijn EM, Garcia Lora AM, van Hall $\mathrm{T}$ (2016) The urgent need to recover MHC class I in cancers for effective immunotherapy. Curr Opin Immunol 39:44-51. https:// doi.org/10.1016/j.coi.2015.12.007

\section{Affiliations}

\section{Daniel Rojas-Sepúlveda ${ }^{1,2,3} \cdot$ Andrés Tittarelli $^{1,2}$ - María Alejandra Gleisner ${ }^{1,2} \cdot \operatorname{Ignacio~}$ Ávalos ${ }^{1,2}$. Cristián Pereda ${ }^{1,2} \cdot$ Iván Gallegos ${ }^{5}$. Fermín Eduardo González ${ }^{2,4} \cdot$ Mercedes Natalia López $^{1,2}$. Jean Michel Butte ${ }^{6}$. Juan Carlos Roa ${ }^{7,8}$. Paula Fluxá ${ }^{1,2}$ • Flavio Salazar-Onfray ${ }^{1,2}$ (])}

1 Disciplinary Program of Immunology, Institute of Biomedical Sciences, Faculty of Medicine, Universidad de Chile, Independencia 1027, building H, Third floor, 8380453 Santiago, Chile
2 Millennium Institute on Immunology and Immunotherapy, Universidad de Chile, 8380453 Santiago, Chile 
3 Faculty of Science, Universidad San Sebastián, Lota 2465, 7510157 Santiago, Chile

4 Department of Conservative Dentistry, Faculty of Dentistry, Universidad de Chile, 8380492 Santiago, Chile

5 Pathological Anatomy Service, Clinic Hospital, Universidad de Chile, 8380456 Santiago, Chile

6 Department of Surgery, Fundación Arturo López Pérez, Institute of Oncology, 7500921 Santiago, Chile
7 Department of Pathology, School of Medicine, Pontificia Universidad Católica de Chile, 8330023 Santiago, Chile

8 Center for Investigation in Translational Oncology (CITO), Advanced Center for Chronic Diseases (ACCDiS), School of Medicine, Pontificia Universidad Católica de Chile, 8330023 Santiago, Chile 